\title{
Comment to "Sugar-sweetened beverage and diet soda consumption and the 7-year risk for type 2 diabetes mellitus in middle-aged Japanese men"
}

\author{
Cheng Chen
}

Published online: 9 April 2014

(C) Springer-Verlag Berlin Heidelberg 2014

Dear Editor,

Recently, Sakurai et al. [1] examined the association between sugar-sweetened beverage (SSB) and diet soda consumption and the incidence of type 2 diabetes in Japanese men. They concluded that the consumption of diet soda was significantly associated with an increased risk of diabetes in Japanese men; meanwhile, no association was found between SSB consumption and incidence of diabetes. However, the use of BMI in multivariate-adjusted HR analysis may not be optimal in this study. Previous studies have shown that waist circumference is a better predictor for diabetes than BMI. A cohort study indicated that the predictive power of a single measurement of waist circumference was at least equal to that of WHR and BMI combined. More importantly, the waist-NIDDM relation was stronger in subjects with $\mathrm{BMI} \leq 27 \mathrm{~kg} / \mathrm{m}^{2}$ than in subjects with BMI $>27 \mathrm{~kg} / \mathrm{m}^{2}$ [2]. Under the consideration that the participants in this study were relatively lean Japanese people whose mean BMI was no larger than $25 \mathrm{~kg} /$ $\mathrm{m}^{2}$, waist circumference may be a better choice in data analysis. Furthermore, people whose waist circumferences are higher than peers are more likely to consume diet soda instead of regular one to prevent obesity and sugar intakerelated diseases, although their BMI value may not exceed $25 \mathrm{~kg} / \mathrm{m}^{2}$. The association between diet soda consumption and increased incidence of diabetes may be biased by the desire of reducing sugar intake. Thus, the inclusion of waist circumference rather than BMI in data analysis may strengthen the validity of the study.

\section{References}

1. Sakurai M, Nakamura K, Miura K, Takamura T, Yoshita K, Nagasawa SY, Morikawa Y, Ishizaki M, Kido T, Naruse Y, Suwazono Y, Sasaki S, Nakagawa H (2013) Sugar-sweetened beverage and diet soda consumption and the 7-year risk for type 2 diabetes mellitus in middle-aged Japanese men. Eur $\mathrm{J}$ Nutr $53: 251-258$

2. Wei M, Gaskill S, Haffner SM, Stern MP (1997) Waist circumference as the best predictor of non-insulin-dependent diabetes mellitus(NIDDM) compared to body mass index, waist/hip ratio and other anthropometric measurements in Mexican Americans: a 7-year prospective study. Obes Res 5:16-23

A reply to this comment is available at doi:10.1007/s00394-0140681-4.

This comment refers to the article available at doi:10.1007/s00394013-0523-9.

C. Chen $(\bowtie)$

Department of Applied Health Science, Indiana University,

Bloomington, IN, USA

e-mail: chen358@umail.iu.edu 